\title{
Analisis Time Series Pendekatan Error Correction Mechanism: Pengaruh Penerapan ACFTA Terhadap Ekspor Kopi Indonesia ke China Periode 2006-2018
}

\author{
Konita Iladini $^{1, \text { a) }}$, Neli Agustina ${ }^{2, \text { b) }}$ \\ ${ }^{1}$ Program Studi Statistika Politeknik Statistika STIS, Jl. Otto Iskandardinata No. 64C Jakarta 13330.
}

Email: ${ }^{\text {a) }}$ 16.9226@stis.ac.id, ${ }^{\text {b) }}$ neli@stis.ac.id

\begin{abstract}
Indonesia is one of the largest coffee producer and exporter in the world. Some countries that are the main destinations for Indonesia's coffee exports are the largest coffee importers in the world. China as one of the biggest coffee importer countries in the world, has not become the main destination country for Indonesian coffee exports even though coffee consumption in China is increasing. In addition, it is known that Indonesia and China have a free trade agreement called the ASEAN-China Free Trade Area (ACFTA). This study aims to analyze the factors that influence Indonesia's coffee exports to China, including the ACFTA agreement. The results of the study using time series data analysis with Error Correction Mechanism (ECM) approach showed that the world prices of tea, the price of Indonesian coffee exports to China, and the rupiah exchange rate against the yuan significantly influence the volume of Indonesian coffee exports to China in the short term. In the long run, value of Vietnamese coffee exports to China, the world prices of tea, the price of Indonesian coffee exports to China, the rupiah exchange rate against the yuan, and the application of ACFTA significantly influence the volume of Indonesian coffee exports to China. It takes 2 quarters to be corrected towards long-term balance.
\end{abstract}

Keywords: coffee export, ACFTA, Error Correction Mechanism.

\begin{abstract}
Abstrak
Indonesia merupakan salah satu negara dengan produksi dan ekspor kopi terbesar di dunia. Beberapa negara yang menjadi tujuan utama ekspor kopi Indonesia merupakan importir kopi terbesar di dunia. China sebagai salah satu negara importir kopi terbesar di dunia, belum menjadi negara tujuan utama ekspor kopi Indonesia padahal konsumsi kopi di China semakin meningkat. Selain itu, diketahui bahwa Indonesia dan China memiliki kesepakatan perdagangan bebas yang disebut ASEAN-China Free Trade Area (ACFTA). Penelitian ini bertujuan untuk menganalisis faktor-faktor yang memengaruhi ekspor kopi Indonesia ke China, termasuk adanya penerapan kebijakan ACFTA. Hasil penelitian dengan menggunakan analisis data time series pendekatan Error Correction Mechanism (ECM) menunjukkan bahwa harga teh dunia, harga ekspor kopi Indonesia ke China, dan kurs rupiah terhadap yuan berpengaruh signifikan terhadap volume ekspor kopi Indonesia ke China pada jangka pendek. Pada jangka panjang, variabel nilai ekspor kopi Vietnam ke China, harga teh dunia, harga ekspor kopi Indonesia ke China, kurs rupiah terhadap yuan, dan pemberlakuan ACFTA berpengaruh signifikan
\end{abstract}


terhadap volume ekspor kopi Indonesia ke China. Dibutuhkan waktu 2 triwulan agar ketidakseimbangan terkoreksi menuju keseimbangan jangka panjang.

Kata-kata kunci: ekspor kopi, ACFTA, Error Correction Mechanism.

\section{PENDAHULUAN}

Indonesia merupakan salah satu negara dengan produksi kopi terbesar. Rata-rata produksi kopi pada periode 2006-2018 sebesar 662 ribu ton. Dari total produksinya tersebut, rata-rata lebih dari $60 \%$ diekspor ke negara lain. Indonesia merupakan salah satu negara eksportir komoditas kopi terbesar di ASEAN dan dunia pada tahun 2006-2018. Di ASEAN, Indonesia menduduki peringkat kedua setelah Vietnam. Sedangkan di dunia, Indonesia menduduki peringkat ke-4 setelah Brazil, Vietnam, dan Kolombia. (Pusat Data dan Sistem Informasi Pertanian, 2019)

Beberapa negara yang menjadi tujuan utama dari ekspor kopi Indonesia adalah Jepang, Malaysia, Jerman, Mesir, Italia, dan Amerika Serikat. Menurut Pusat Data dan Sistem Informasi Pertanian (2017), pada periode 2011-2016 beberapa negara tujuan utama ekspor kopi Indonesia merupakan importir kopi terbesar di dunia, seperti Amerika Serikat dan Jepang. Salah satu negara yang menjadi importir kopi terbesar dunia periode 2011-2016 tetapi belum menjadi negara tujuan utama ekspor kopi Indonesia adalah China. Rata-rata ekspor kopi Indonesia ke China periode 2006-2018 hanya sekitar 6,4 ribu ton atau 1,4\% dari total ekspor kopi Indonesia. Dari total ekspor kopi negara di dunia, Indonesia berkontribusi sebesar $12 \%$ pada periode 2006-2018.

China dikenal sebagai negara dengan tradisi minum teh, tetapi konsumsi kopi di China beberapa tahun terakhir juga terus mengalami peningkatan. Hal tersebut terjadi karena pergeseran budaya dari sebagian penduduk usia muda yang mulai mengonsumsi kopi sebagai gaya hidup (Zhu, 2018). Kebutuhan kopi di China salah satunya dapat digambarkan melalui total ekspor kopi negara-negara di dunia ke China. Dari tahun 2006 sampai 2018, volume ekspor kopi dunia ke China memiliki tren yang positif. Puncaknya terjadi pada tahun 2017, yaitu sebesar 85.989 ton.

Melihat Indonesia sebagai salah satu negara dengan produksi kopi terbesar di dunia dan konsumsi kopi di China yang terus meningkat, dapat menjadi peluang bagi Indonesia untuk meningkatkan ekspor kopi ke China yang selama ini masih belum menjadi negara tujuan utama. Salah satu harapan yang mendukung peningkatan tersebut adalah dengan kebijakan perdagangan bebas. ASEAN-China Free Trade Area (AFCTA) menjadi salah satu bentuk kesepakatan perdagangan bebas internasional yang diikuti oleh Indonesia. ACFTA merupakan suatu bentuk kesepakatan kerjasama antara negara anggota ASEAN dengan China untuk mewujudkan kawasan perdagangan bebas yaitu dengan mengurangi atau menghilangkan hambatan-hambatan perdagangan barang, baik dalam bentuk tarif maupun non-tarif, peningkatan dalam bidang pasar jasa, investasi sekaligus peningkatan aspek kerjasama ekonomi dalam rangka mendorong dan meningkatkan kesejahteraan masyarakat ASEAN dan Cina.

Beberapa penelitian terkait diantaranya Bowo (2012) telah melakukan penelitian tentang dampak penerapan ASEAN-China Free Trade Area (ACFTA) terhadap nilai perdagangan Indonesia atas China dengan studi kasus beberapa komoditas terbesar menggunakan analisis data panel dengan pendekatan Random Effect. Hasilnya adalah variabel Produk Domestik Bruto China Riil (PDBC) dan pemberlakuan ACFTA (ACFTA) secara signifikan mempengaruhi nilai ekspor komoditas terpilih Indonesia ke China (XCHINA). Sedangkan variabel nilai tukar riil Rupiah terhadap Yuan China (KURS) tidak signifikan. Hussien (2015) melakukan penelitian tentang determinan ekspor kopi di Ethiopia. Data yang digunakan adalah data sekunder dengan data tahunan selama periode 1965-2005. Analisis yang digunakan adalah analisis time series dengan pendekatan Error Correction Model (ECM). Hasilnya adalah pasokan ekspor kopi Ethiopia dalam jangka pendek ditentukan oleh nilai tukar riil, arus masuk modal asing, pendapatan riil, dan jangka waktu perdagangan. Sedangkan dalam jangka panjang ditentukan oleh harga domestik, nilai tukar riil, pendapatan riil dan jangka waktu perdagangan. Ginting (2016) melakukan penelitian tentang ekspor kopi Indonesia ke lima negara ASEAN tahun 1997-2014. Data yang digunakan adalah data sekunder tahunan periode 1997 sampai 2014. Berdasarkan hasil analisis indeks RCA (Revealed Comparative Advantage), yaitu indeks daya 
saing ekspor suatu komoditas dari suatu negara, diketahui bahwa kinerja ekspor kopi Indonesia hanya memiliki keunggulan komparatif di atas rata-rata dunia di negara tujuan Malaysia. Dan berdasarkan hasil analisis regresi data panel menunjukkan bahwa variabel harga teh, PDB riil, dan indeks RCA signifikan berpengaruh secara positif terhadap ekspor komoditi kopi Indonesia. Variabel harga riil ekspor kopi Indonesia dan nilai tukar riil negara mitra dagang signifikan berpengaruh negatif terhadap ekspor komoditi kopi Indonesia. Sedangkan variabel produksi kopi domestik tidak signifikan berpengaruh terhadap ekspor komoditi kopi Indonesia.

Berdasarkan penjelasan di atas, maka penelitian ini fokus kepada faktor-faktor yang memengaruhi ekspor kopi Indonesia ke China, salah satunya dengan adanya penerapan kebijakan ACFTA. Variabelvariabel yang digunakan pada penelitian ini diperoleh dari penelitian-penelitian terdahulu. Perbedaan penelitian ini dengan penelitian-penelitian terdahulu adalah hanya dipilih komoditas kopi dengan tujuan ekspor ke China saja. Selain itu, dalam penelitian ini menambahkan variabel independen ekspor kopi dari negara kompetitor yaitu Vietnam di pasar China. Tujuan dari penelitian ini adalah untuk mengetahui gambaran umum ekspor kopi Indonesia ke China sebelum dan sesudah penerapan kebijakan ACFTA serta untuk menganalisis faktor-faktor yang memengaruhi ekspor komoditas kopi Indonesia ke China, karena China bukan merupakan negara tujuan utama. Selain itu, dengan adanya kebijakan perdagangan bebas ACFTA, penulis ingin mengetahui apakah kebijakan tersebut berpengaruh terhadap ekspor kopi di Indonesia. Metode yang digunakan dalam penelitian adalah Error Correction Mechanism (ECM). Metode tersebut digunakan karena konvergen dengan teori ekonomi. Kelebihan dari ECM adalah dapat melihat fenomena ekonomi dalam jangka panjang dan jangka pendek, serta dapat menyelesaikan permasalahan pada model yang tidak stasioner. Kelemahan dari metode ECM adalah error yang dihasilkan pada model jangka panjang akan dilanjutkan pada regresi jangka pendek.

\section{METODOLOGI PENELITIAN}

\section{Data dan Variabel Penelitian}

Komoditas kopi yang dimaksud dalam penelitian ini adalah semua jenis kopi yang termasuk dalam kode Harmonize System (HS) 090111 (Kopi; tidak dipanggang atau dihilangkan kafeinnya), 090112 (Kopi; dihilangkan kafeinnya, tidak dipanggang), 090121 (Kopi; dipanggang, tidak dihilangkan kafeinnya), 090122 (Kopi; dipanggang, dihilangkan kafeinnya), dan 090190 (Kopi; sekam dan kulit, pengganti kopi yang mengandung kopi).

Penelitian ini menggunakan Error Correction Mechanism (ECM) dengan variabel dependen volume ekspor kopi Indonesia ke China. Variabel independen yang digunakan adalah nilai ekspor kopi Vietnam ke China, harga teh dunia, harga ekspor kopi Indonesia ke China, nilai tukar riil rupiah terhadap yuan, dan dummy penerapan ACFTA. Satuan waktu yang digunakan dalam penelitian ini adalah triwulanan, dengan periode triwulan ke-1 tahun 2006 sampai triwulan ke-4 tahun 2018, sehingga jumlah observasi sebanyak 52 unit.

Jenis data yang digunakan adalah data time series, yang merupakan data sekunder yang dikumpulkan dari berbagai sumber, antara lain: Badan Pusat Statistik, World Bank, UN Comtrade, dan International Monetary Fund. Variabel volume ekspor kopi Indonesia ke China (kg) diperoleh dari Publikasi BPS, nilai ekspor kopi Vietnam ke China (USD) diperoleh dari UN Comtrade, harga ekspor kopi Indonesia ke China diperoleh dengan cara membagi nilai FOB ekspor kopi Indonesia ke China dengan volume ekspor kopi Indonesia ke China (USD/Kg) dengan nilai FOB (Free on Board) dan volume ekspor kopi Indonesia ke China diperoleh dari data Publikasi BPS, harga teh dunia (USD/kg ) diperoleh dari World Bank, dan nilai tukar riil rupiah terhadap yuan (IDR/CNY) diperoleh dari International Monetary Fund. Dummy penerapan ACFTA dimulai dari triwulan ke-1 tahun 2010 sampai triwulan ke-4 tahun 2018. Periode tanpa kebijakan ACFTA dinotasikan dengan "0", sedangkan periode dengan kebijakan ACFTA dinotasikan dengan " 1 ". 


\section{Metode Analisis}

Metode analisis yang digunakan dalam penelitian adalah analisis deskriptif dan Error Correction Mechanism (ECM). Dengan pemodelan ECM, dapat diketahui bagaimana pengaruh nilai ekspor kopi Vietnam ke China, harga teh dunia, harga ekspor kopi Indonesia ke China, nilai tukar riil rupiah terhadap yuan, dan dummy penerapan ACFTA terhadap besarnya volume ekspor kopi Indonesia ke China baik pada jangka panjang maupun jangka pendek. Sebelum dilakukan pemodelan ECM, data variabel ditransformasi dengan logaritma natural. Hal ini dilakukan karena data yang tidak ditransformasi melanggar beberapa asumsi sehingga menjadi tidak terpenuhi.

Pada perilaku ekonomi seringkali ditemukan ketidakseimbangan antarvariabel dalam jangka pendek karena ketidakmampuan pelaku ekonomi untuk menyesuaikan perubahan-perubahan yang terjadi dalam variabel ekonomi dengan segera. ECM adalah salah satu metode analisis time series yang digunakan untuk melakukan rekonsiliasi perilaku variabel ekonomi jangka pendek dengan variabel ekonomi jangka panjang. Tujuan menggunakan metode ECM untuk mengoreksi penyimpangan terhadap keseimbangan jangka panjang. (Enders, 2014)

ECM dapat menyelesaikan masalah dalam spurious regression (regresi lancung) yang menyebabkan variabel-variabel seolah-olah menjadi signifikan berpengaruh padahal tidak ada teori yang melandasi. Regresi palsu dapat diindikasikan dengan nilai $\mathrm{R}^{2}$ dan nilai Durbin Watson, sehingga jika $\mathrm{R}^{2}$ > Durbin Watson patut dicurigai bahwa regresi yang terbentuk adalah palsu. (Gujarati, 2004)

Langkah pertama yang dilakukan dalam metode ECM adalah menguji stasioneritas dari variabelvariabel yang digunakan dengan menggunakan uji ADF (Augmented Dickey-Fuller). Syarat agar dapat dilakukan pemodelan ECM adalah keseluruhan variabel tidak boleh stasioner pada level, minimal pada difference pertama. Dalam penelitian ini stasioner pada difference pertama, selanjutnya pembentukan model jangka panjang dengan metode estimasi OLS. Dalam model jangka panjang, variabel independen diregresikan terhadap variabel dependen pada tingkat level. Persamaan jangka panjang yang terbentuk adalah sebagai berikut:

$$
L_{N E X P I D}=\beta_{0}+\beta_{1} L N E X P V_{t}+\beta_{2} L_{N H T E H_{t}}+\beta_{3} L N H E X P_{t}+\beta_{4} L N K U R S_{t}+\beta_{5} \text { ACFTA }_{t}+\varepsilon_{t}
$$

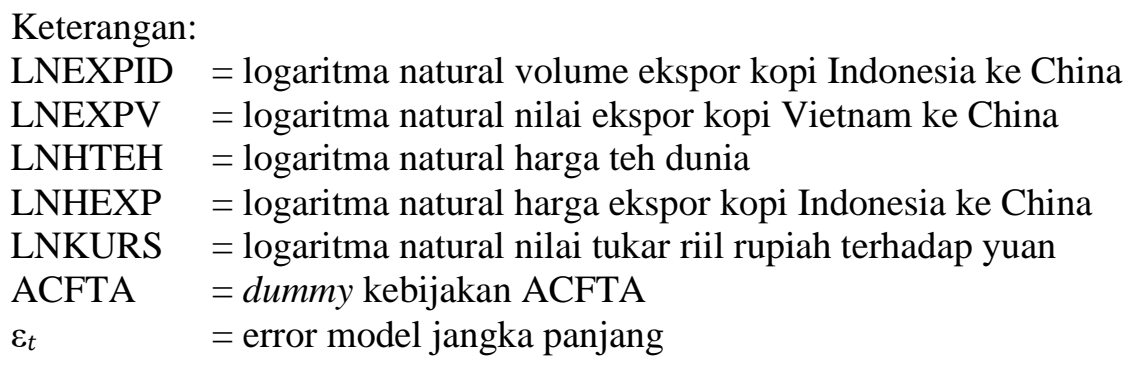

Selanjutnya pengujian kointegrasi dengan menguji stasioneritas residual persamaan jangka panjang. Apabila residual persamaan jangka panjang stasioner pada level, maka dapat dikatakan terdapat kointegrasi di antara variabel-variabel yang digunakan dalam penelitian. Setelah dilakukan uji kointegrasi, pembentukan model ECM yang menjadi persamaan jangka pendek. Model ECM dibentuk dengan memasukkan lag pertama dari residual persamaan jangka panjang ke dalam persamaan regresi variabel-variabel yang stasioner pada difference yang sama (penelitian ini pada difference pertama). Model ECM yang terbentuk seperti berikut:

$$
\begin{aligned}
\triangle L N E X P I D_{t}= & \beta_{0}+\beta_{1} \Delta L N E X P V_{t}+\beta_{2} \Delta L N H T E H_{t}+\beta_{3} \Delta L N H E X P_{t}+\beta_{4} \Delta L N K U R S_{t}+\beta_{5} \text { ACFTA }_{t} \\
& +\beta_{6} E C T+u_{t}
\end{aligned}
$$

Keterangan:

$\Delta \quad=$ difference 
LNEXPID = logaritma natural volume ekspor kopi Indonesia ke China

LNEXPV = logaritma natural nilai ekspor kopi Vietnam ke China

LNHTEH = logaritma natural harga teh dunia

LNHEXP = logaritma natural harga ekspor kopi Indonesia ke China

LNKURS = logaritma natural nilai tukar riil rupiah terhadap yuan

ACFTA $=$ dummy kebijakan ACFTA

ECT $=$ error correction term

$\mathrm{u}_{\mathrm{t}} \quad=$ error model jangka pendek

Dalam model ECM, nilai koefisien $\beta_{6}$ harus signifikan secara statistik dengan nilai negatif, kurang dari satu. Jika syarat tersebut dilanggar, variabel-variabel akan semakin menjauhi garis keseimbangan dan membentuk ketidakseimbangan baru sehingga model tidak dapat digunakan. Selanjutnya adalah uji signifikansi parameter secara simultan menggunakan uji $\mathrm{F}$ dan pengujian signifikansi parameter secara parsial. Kemudian dilanjutkan dengan pengujian asumsi klasik yaitu normalitas, nonautokorelasi, homoskedastisitas, dan nonmultikolinieritas.

\section{HASIL DAN PEMBAHASAN}

\section{Gambaran Umum Ekspor Kopi Indonesia ke China}

Berdasarkan GAMBAR 1, nilai dan volume ekspor kopi Indonesia ke China cenderung berfluktuasi sejak tahun 2006 hingga tahun 2009. Periode tersebut merupakan periode sebelum kebijakan ACFTA diberlakukan secara efektif. Rata-rata volume ekspor kopi pada periode tersebut sebesar 371,2 ton dengan nilai ekspor rata-rata sebesar 623 ribu US\$. Volume ekspor setelah kebijakan ACFTA efektif diberlakukan juga cenderung fluktuatif, tetapi jumlahnya meningkat. Ratarata volume ekspor kopi pada periode setelah penerapan ACFTA sebesar 2.132,4 ton dengan nilai ekspor rata-rata sebesar 4.631,3 ribu US dolar. Peningkatan tersebut tidak langsung terjadi saat awal kebijakan ACFTA diberlakukan. Peningkatan secara drastis dimulai pada tahun 2012 triwulan ketiga dengan volume ekspor sebesar 5.329 ton. Menurut Desnky (2018), salah satu penyebabnya adalah produksi kopi Indonesia meningkat karena peran pemerintah membantu petani dalam peningkatan mutu kopi dan pengenalan teknologi pertanian. Selain itu peningkatan konsumsi kopi di China menjadi 47 gram per kapita dengan jumlah penduduk sekitar 1,3 miliar atau hampir dua kali lipat dibandingkan konsumsi kopi sebelum tahun 2010 (Zhu, 2018).

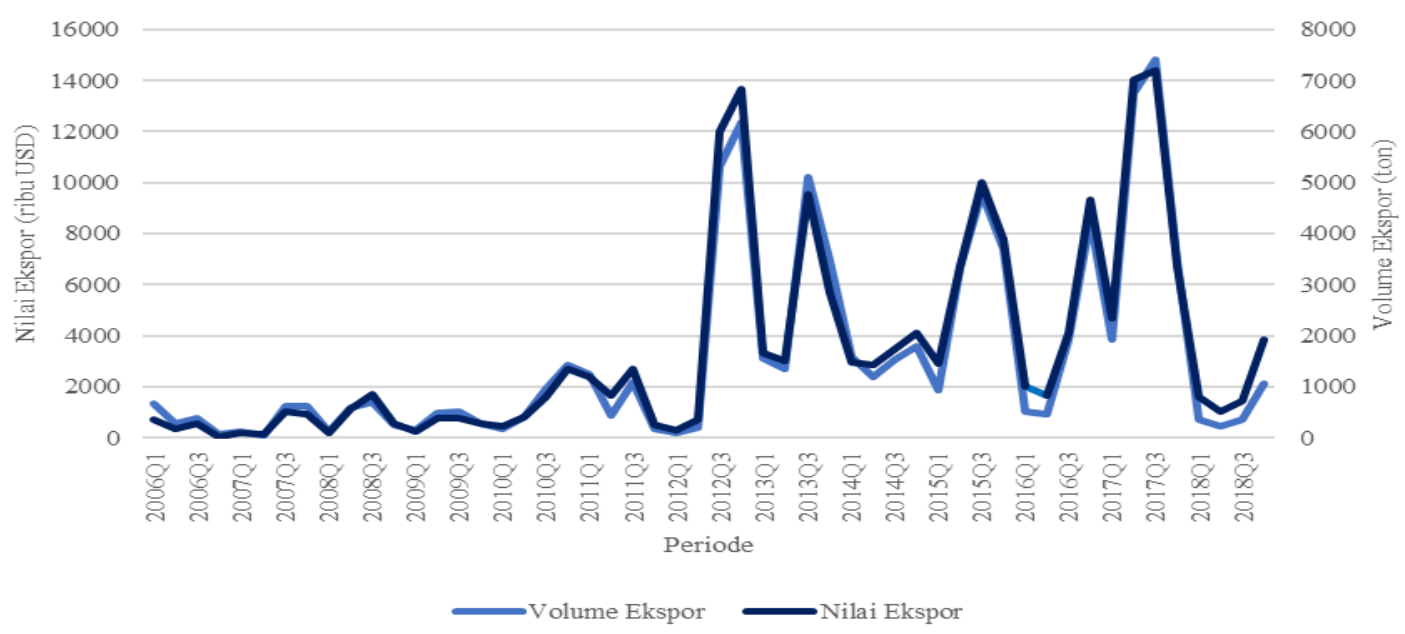

GAMBAR 1. Nilai (ribu USD) dan Volume (ton) ekspor kopi Indonesia ke China periode 2006-2018

Pada GAMBAR 2 juga menunjukkan setiap triwulan ketiga, pertumbuhan ekspor kopi memiliki pola peningkatan yang berulang. Hal tersebut terjadi karena kopi merupakan tanaman musiman dengan masa panen pada bulan Mei sampai September tergantung kondisi iklim setempat dan jenis 
kopi. Umumnya panen kopi jenis robusta lebih lambat dibandingkan jenis arabika. Panen kopi arabika sekitar bulan Mei-Juli, sedangkan panen kopi robusta sekitar bulan Juli-September. (Rahardjo, 2017)

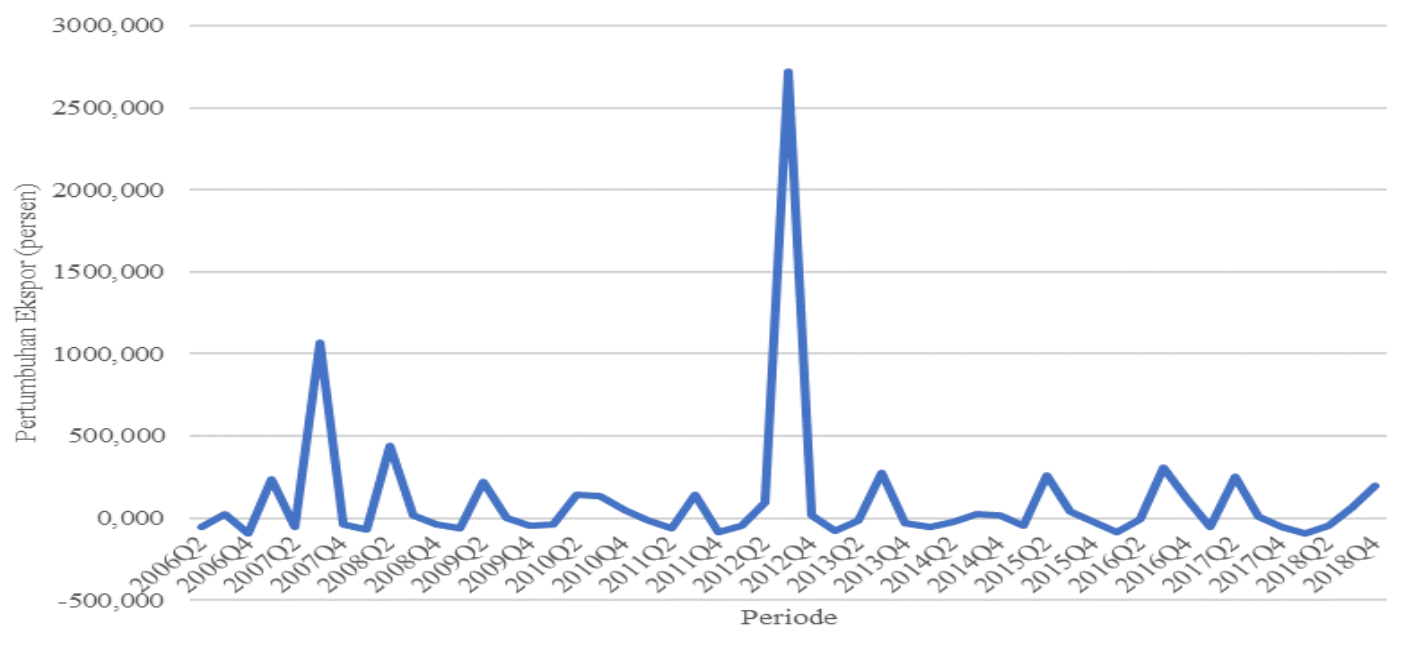

GAMBAR 2. Pertumbuhan ekspor kopi Indonesia ke China periode 2006-2018

\section{Gambaran Umum Nilai Ekspor Kopi Vietnam ke China}

Salah satu negara yang menjadi kompetitor Indonesia dalam mengekspor kopi ke China yaitu Vietnam. GAMBAR 3 menunjukkan nilai ekspor kopi Indonesia dan Vietnam ke China periode 20062018. Nilai ekspor kopi Vietnam selalu di atas ekspor kopi Indonesia karena jumlah produksi dan ekspor kopi Indonesia lebih rendah meskipun luas areal kopi lebih besar dibandingkan Vietnam sehingga produktivitas kopi Indonesia baru mencapai $25 \%$ dari potensi produksinya. Produktivitas kopi di Vietnam sebesar lebih dari 2 ton/ha sedangkan di Indonesia hanya sekitar $500 \mathrm{~kg} / \mathrm{ha}$ (Hanani dkk., 2013). Nilai ekspor Vietnam ke China mengalami peningkatan drastis pada tahun 2016, salah satunya karena kondisi cuaca berupa kekeringan terburuk dalam 20 tahun sehingga menyebabkan harga kopi naik karena pasokan kopi berkurang (ICO, 2019). Selain itu, peningkatan ekspor kopi juga diduga karena penerapan ACFTA di Vietnam pada tahun 2015.

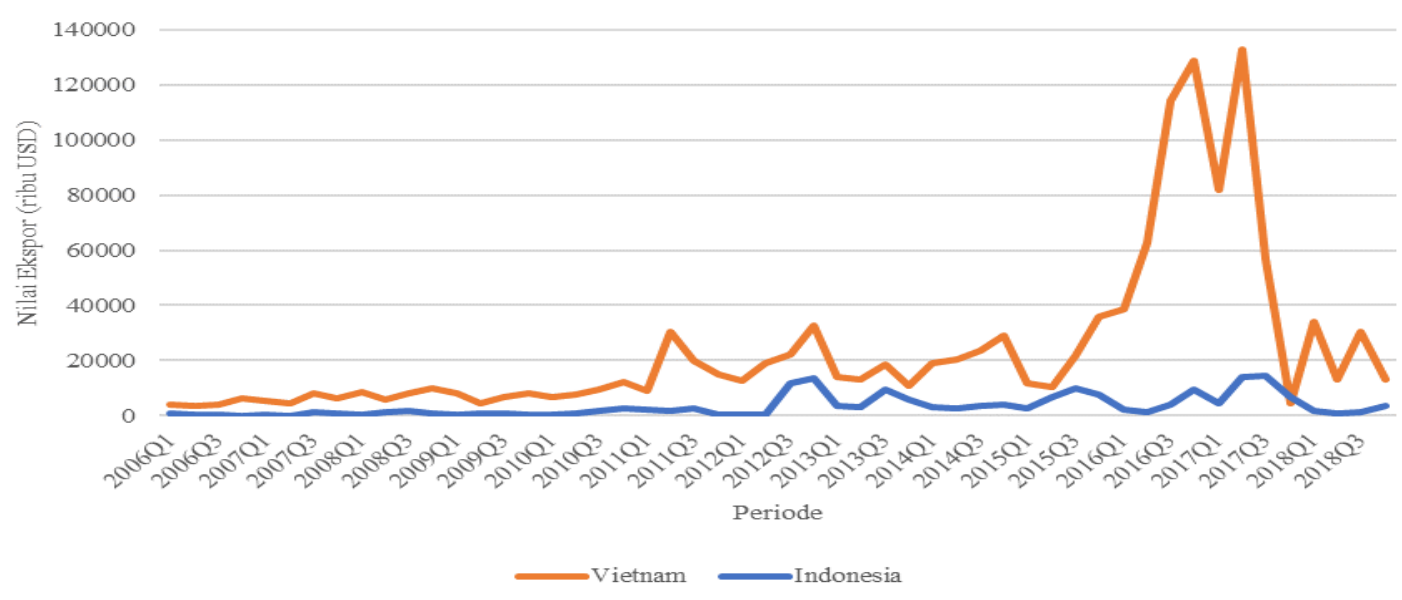

GAMBAR 3. Nilai ekspor kopi Indonesia dan Vietnam ke China periode 2006-2018

\section{Gambaran Umum Nilai Tukar Riil Rupiah Terhadap Yuan China}

Dari tahun 2006 hingga tahun 2018 nilai tukar riil rupiah cenderung mengalami depresiasi. Menurut Rahmawan (2017), depresiasi rupiah terhadap yuan terjadi karena adanya krisis global yang 
terjadi di Amerika Serikat. Puncak depresiasi tersebut diikuti oleh penurunan ekspor kopi Indonesia ke China sebesar 107,8 ton. Sementara depresiasi yang puncaknya pada tahun 2015 disebabkan oleh melemahnya pertumbuhan ekonomi di kawasan Asia. Puncak depresiasi kedua ini diikuti dengan peningkatan ekspor kopi Indonesia ke China sebesar 1.452,98 ton. Karena terjadi ketidaksesuaian hubungan antara nilai tukar riil rupiah terhadap yuan dengan ekspor kopi Indonesia ke China dalam analisis deskriptif, maka perlu dilakukan uji secara statistik.

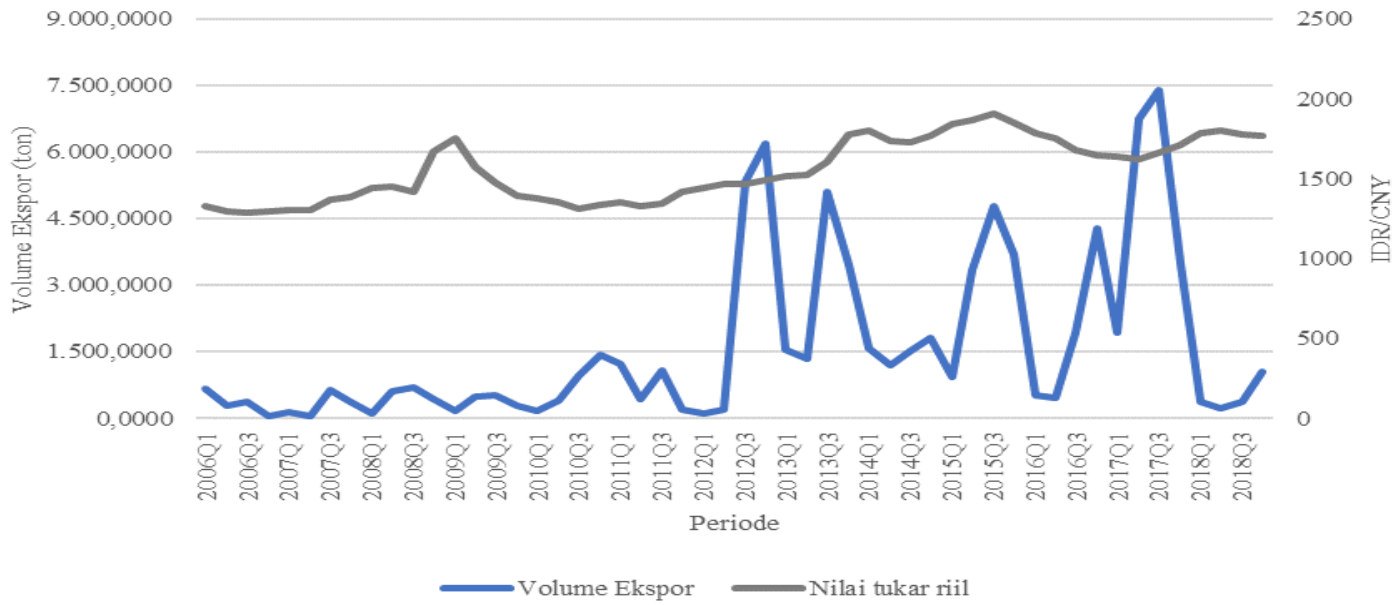

GAMBAR 4. Nilai tukar riil rupiah terhadap yuan (IDR/CNY) dan volume ekspor kopi Indonesia ke China (ton) periode 2006- 2018

\section{Gambaran Umum Harga Teh Dunia}

Sebagai barang substitusi dari kopi, perkembangan harga teh juga perlu ditinjau. Berdasarkan GAMBAR 5, pertumbuhan harga teh dunia periode 2006-2018 cenderung fluktuatif. Rata-rata harga teh pada periode tersebut sebesar 2,65 US\$/kg. Penurunan harga teh secara drastis pada akhir tahun 2008 menjadi 1,92 US\$/kg diikuti oleh penurunan ekspor kopi Indonesia ke China sebesar 424,34 ton. Sedangkan puncak peningkatan harga teh pada pertengahan tahun 2009 menjadi 3,15 US\$/kg diikuti oleh peningkatan ekspor kopi Indonesia ke China sebesar 11,02 ton.

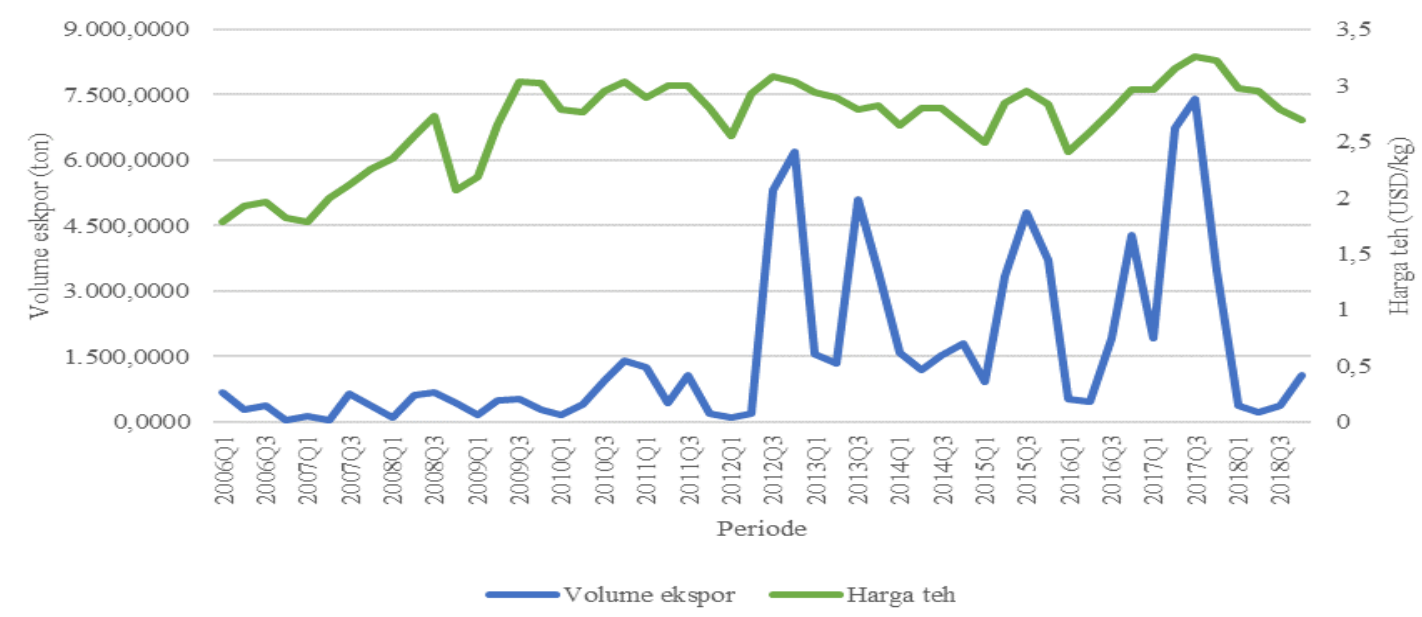

GAMBAR 5. Harga teh dunia (USD/kg) dan volume ekspor kopi Indonesia ke China (ton) periode 2006- 2018

\section{Gambaran Umum Harga Ekspor Kopi Indonesia ke China}

Harga ekspor kopi Indonesia ke China periode 2006-2018 ditunjukkan oleh GAMBAR 6. Pertumbuhan harga ekspor kopi Indonesia juga mengalami fluktuasi seperti harga teh dunia, namun 
harga ekspor kopi cenderung dibawah harga teh. Rata-rata harga ekspor kopi Indonesia ke China periode 2006-2018 adalah 2,24 US\$/kg. Penurunan harga ekspor kopi secara drastis pada pertengahan tahun 2015 dan 2016 diikuti oleh peningkatan ekspor kopi Indonesia ke China masing-masing sebesar $2.409,49$ ton dan $1.457,89$ ton. Sedangkan peningkatan harga ekspor kopi secara drastis pada awal tahun 2016 dan 2018 diikuti oleh penurunan ekspor kopi Indonesia ke China masing-masing sebesar $3.182,37$ ton dan 3.106,1 ton. Selain itu, hampir di setiap peningkatan volume ekspor kopi, harga ekspor kopi juga mengalami penurunan karena saat pasokan kopi tinggi pada masa panen (triwulan ketiga) menyebabkan harga kopi menjadi lebih murah.

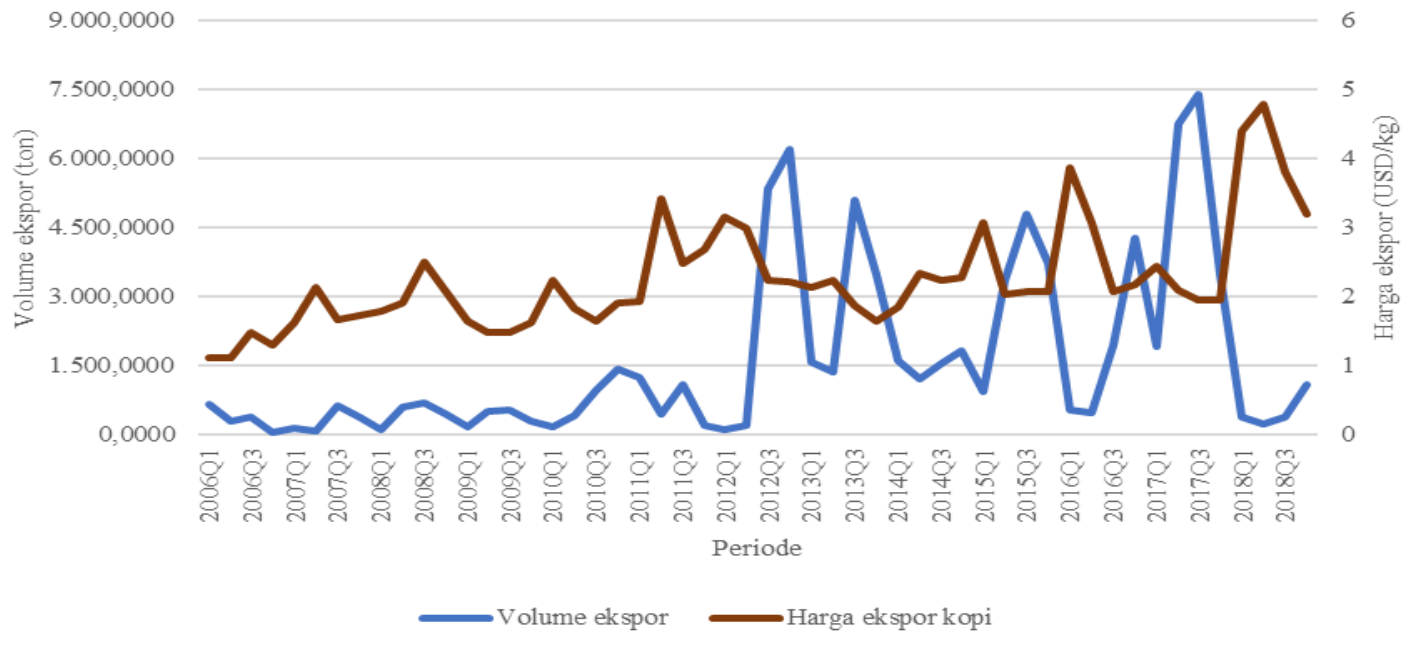

GAMBAR 6. Harga (USD/kg) dan volume (ton) ekspor kopi Indonesia ke China periode 2006- 2018

Faktor-faktor yang Memengaruhi Ekspor Kopi Indonesia ke China

Pemodelan Error Correction Mechanism (ECM) digunakan untuk mengetahui pengaruh dari nilai ekspor kopi Vietnam ke China, harga teh dunia, harga ekspor kopi Indonesia ke China, nilai tukar riil rupiah terhadap yuan, dan dummy pemberlakuan ACFTA terhadap volume ekspor kopi Indonesia ke China.

TABEL 1. Hasil uji stasioneritas pada tingkat level dan first difference

\begin{tabular}{ccccc}
\hline & \multicolumn{2}{c}{ Data level } & \multicolumn{2}{c}{ Data first difference } \\
\hline Variabel & $p$-value & Keterangan & $p$-value & Keterangan \\
\hline LNEXPID & 0.8664 & Tidak Stasioner & 0.0000 & Stasioner \\
LNEXPV & 0.7670 & Tidak Stasioner & 0.0000 & Stasioner \\
LNHTEH & 0.8879 & Tidak Stasioner & 0.0000 & Stasioner \\
LNHEXP & 0.4598 & Tidak Stasioner & 0.0000 & Stasioner \\
LNKURS & 0.9143 & Tidak Stasioner & 0.0000 & Stasioner \\
\hline
\end{tabular}

Pengujian stasioneritas data dilakukan untuk menghindari terjadinya spurious regression (regresi palsu). TABEL 1 menunjukkan hasil pengujian stationeritas pada tingkat level dan first difference. Berdasarkan hasil uji ADF diketahui bahwa pada tingkat level semua variabel belum stasioner karena memiliki nilai p-value yang lebih dari 0,05 sehingga gagal tolak $\mathrm{H}_{0}$ atau terdapat unit root. Sedangkan hasil pengujian stationeritas pada first difference menunjukkan bahwa semua variabel telah stasioner pada first difference. Hal tersebut dapat diketahui dari nilai p-value yang kurang dari 0,05 sehingga keputusan adalah tolak $\mathrm{H}_{0}$. Sehingga dapat disimpulkan bahwa data telah stasioner pada first difference.

TABEL 2. Hasil estimasi parameter jangka panjang

Variabel Koefisien se t-statistik p-value




\begin{tabular}{lcccc}
\hline C & $-7,2091$ & 3,0876 & $-2,3349$ & 0,0240 \\
LNEXPV & 0,3826 & 0,1574 & 2,4309 & 0,0190 \\
LNHTEH & 3,1771 & 0,9451 & 3,3617 & 0,0016 \\
LNHEXP & $-2,6694$ & 0,4264 & $-6,2608$ & 0,0000 \\
LNKURS & 3,3796 & 1,0141 & 3,3326 & 0,0017 \\
ACFTA & 0,3732 & & & \\
Prob (F-stat) & 0,0000 & 0,1678 & 2,2244 & 0,0311 \\
Adjusted R-Squared & 0,6744 & & & \\
\hline
\end{tabular}

Setelah dilakukan uji stasioneritas, kemudian dilakukan estimasi parameter dari persamaan jangka panjang. Berdasarkan hasil regresi jangka panjang pada TABEL 2 maka dapat dituliskan persamaan sebagai berikut.

$$
\begin{aligned}
& \widehat{\text { LNEXPID }}_{t}=-7,2091+0,3732 \text { ACFTA }_{t}^{*}+0,3826 \text { LNEXPV }_{t}^{*}-2,6694 \text { LNHEXP }_{t}+ \\
& 3,1771 \text { LNHTEH }^{*}+3,3796 \text { LNKURS }^{*}{ }_{t}
\end{aligned}
$$

Keterangan: *) signifikan pada $\alpha 5$ persen

TABEL 3. Hasil pengujian kointegrasi

\begin{tabular}{cccc}
\hline Variabel & Statistik Uji & $\boldsymbol{p}$-value & Keterangan \\
\hline $\boldsymbol{\varepsilon}$ & $-5,7203$ & 0,0000 & Stasioner \\
\hline
\end{tabular}

Uji kointegrasi dilakukan untuk mengetahui ada tidaknya hubungan jangka panjang antara variabel-variabel independen dan dependen. Hasil pengujian kointegrasi pada TABEL 3 menunjukkan bahwa p-value dari statistik uji kurang dari 0,05. Artinya variabel ECT telah stasioner pada level untuk tingkat signifikansi 5 persen. Oleh karena itu, dapat disimpulkan bahwa terdapat kointegrasi atau hubungan keseimbangan jangka panjang antara variabel-variabel independen dan variabel dependen.

TABEL 4. Hasil estimasi persamaan jangka pendek (model ECM)

\begin{tabular}{lllll}
\hline \multicolumn{1}{c}{ Variabel } & Koefisien & SE & t-statistik & p-value \\
\hline C & $-0,0521$ & 0,0843 & $-0,6183$ & 0,5396 \\
D(LNEXPV) & 0,2362 & 0,1522 & 1,5514 & 0,1280 \\
D(LNHEXP) & $-2,3112$ & 0,4489 & $-5,1482$ & 0,0000 \\
D(LNHTEH) & 4,2247 & 1,5908 & 2,6557 & 0,0110 \\
D(LNKURS) & 6,4921 & 3,2632 & 1,9894 & 0,0529 \\
ACFTA & 0,0555 & 0,0979 & 0,5671 & 0,5735 \\
ECT & $-0,8787$ & 0,1616 & $-5,4369$ & 0,0000 \\
Prob $(\boldsymbol{F}$-stat) & 0,0000 & & & \\
Adjusted $\boldsymbol{R}$-Squared & 0,6102 & & & \\
\hline
\end{tabular}

Pemodelan persamaan jangka pendek (Model ECM) dibentuk untuk memperbaiki suatu model yang variabel-variabelnya tidak stasioner. Selain itu juga dapat mengetahui variabel mana yang berpengaruh signifikan pada variabel dependen dalam jangka pendek. Model ini dapat dibentuk jika terdapat kointegrasi dalam jangka panjang. Berdasarkan hasil regresi jangka pendek (model ECM) pada TABEL 4 dapat dituliskan persamaannya sebagai berikut.

$$
\begin{aligned}
& \triangle \widehat{L N E P I D}_{t}=-0,0521+0,0555 \text { ACFTA }_{t}+0,23624 \text { LNEXPV }_{t}-2,31124 \text { LNHEXP }_{t}+ \\
& 4,22474 \text { LNHTEH }_{t}^{*}+6,4921 \Delta \text { LNKURS }_{t}-0,8787 \text { ECT }_{t-1}^{*}
\end{aligned}
$$


Keterangan:

*) signifikan pada $\alpha=5$ persen

Setelah melakukan estimasi parameter untuk memperoleh model ECM, perlu dilakukan pengujian asumsi klasik. Pengujian tersebut dilakukan untuk memastikan bahwa estimator yang diperoleh telah bersifat BLUE (Best Linier Unbiased Estimator). Asumsi yang diuji adalah normalitas, nonautokorelasi, homoskedastisitas, dan nonmultikolinieritas. Dari TABEL 5 dapat diketahui bahwa asumsi normalitas, nonautokorelasi, homoskedastisitas, dan nonmultikolinieritas telah terpenuhi.

TABEL 5 Hasil uji asumsi klasik

\begin{tabular}{lccc}
\multicolumn{1}{c}{ Uji Asumsi } & p-value & Keputusan & Keterangan \\
\hline Normalitas & 0,9938 & Gagal Tolak $\mathrm{H}_{0}$ & Terpenuhi \\
Nonautokorelasi & 0,2871 & Gagal Tolak $\mathrm{H}_{0}$ & Terpenuhi \\
Homoskedastisitas & 0,0834 & Gagal Tolak $\mathrm{H}_{0}$ & Terpenuhi \\
Nonmultikolinieritas & VIF & & Terpenuhi \\
D(LNEXPV) & 1.046466 & & \\
D(LNHEXP) & 1.201595 & & \\
D(LNHTEH) & 1.639664 & & \\
D(LNKURS) & 1.793159 & & \\
ACFTA & 1.081231 & & \\
ECT & 1.334328 & & \\
\hline
\end{tabular}

Dari persamaan jangka pendek dapat diketahui bahwa nilai koefisien dari ECT sebesar -0,8787. Nilai tersebut sudah memenuhi syarat ECM yaitu signifikan, negatif, dan kurang dari satu. Model ECM juga menunjukkan bahwa nilai p-value dari F Statistik sebesar 0,00. Keputusan dari uji-F adalah tolak H0, dengan tingkat signifikansi 5 persen dapat disimpulkan bahwa minimal terdapat satu variabel independen yang signifikan memengaruhi volume ekspor kopi Indonesia ke China.

Secara parsial, dengan signifikansi 5 persen dapat disimpulkan bahwa variabel harga teh dunia berpengaruh positif dan signifikan terhadap volume ekspor Indonesia ke China, sedangkan harga ekspor kopi Indonesia ke China berpengaruh negatif dan signifikan terhadap volume ekspor kopi Indonesia ke China. Dengan signifikansi 10 persen, nilai tukar riil rupiah terhadap yuan berpengaruh positif dan signifikan terhadap volume ekspor Indonesia ke China.

Nilai ekspor kopi Vietnam berpengaruh signifikan terhadap volume ekspor kopi Indonesia ke China dalam jangka panjang tetapi tidak berpengaruh signifikan dalam jangka pendek. Ini terjadi karena salah satu faktor yang memengaruhi ekspor adalah selera konsumen. Kopi Indonesia adalah kopi yang berkarakter lebih kuat dibanding kopi Vietnam sehingga kopi Vietnam tidak langsung dapat digantikan dengan kopi Indonesia (Atmadji dkk, 2019). Nilai ekspor kopi Vietnam yang berpengaruh positif tidak sesuai dengan hipotesis penelitian karena Vietnam merupakan negara kompetitor Indonesia di pasar China. Hal tersebut terjadi karena menurut perhitungan RCA, nilai RCA kopi Vietnam menurun dan hampir sama dengan nilai RCA Indonesia. Dalam perhitungan RCA tersebut juga diketahui bahwa rata-rata nilai RCA Indonesia meningkat setelah penerapan ACFTA, dari 4,71 pada periode 2006-2009 menjadi 7,69 pada periode 2010-2018. Artinya, daya saing kopi Indonesia di pasar China semakin meningkat setelah penerapan ACFTA secara efektif.

Penerapan ACFTA berpengaruh signifikan terhadap volume ekspor Indonesia ke China dalam jangka panjang tetapi tidak berpengaruh signifikan dalam jangka pendek. Hal ini sesuai dengan penelitian Setiawan dan Sugiarti (2016) yang menyatakan bahwa ACFTA tidak signifikan memengaruhi ekspor kopi karena ekspor kopi Indonesia lebih terkonsentrasi ke negara lain, seperti Amerika Serikat, Jepang, dan Jerman. Selain itu, menurut penelitian Nabila (2017), dalam hal perdagangan barang, Tiongkok (China) lebih dapat mengoptimalkan penerapan ACFTA sehingga manfaat yang diperoleh China lebih banyak dari Indonesia dalam 75 jangka pendek. Dalam penelitian tersebut juga melakukan analisis menggunakan model ARIMA dan dalam tiga tahun setelah penerapan ACFTA (dalam jangka panjang) justru bisa meningkatkan nilai ekspor Indonesia ke China.

Indonesia tidak dapat memanfaatkan penerapan ACFTA secara maksimal dalam jangka pendek karena pemerintah tidak mempersiapkan kondisi ekonomi nasional secara optimal. Buruknya kualitas 
infrastruktur, tingginya suku bunga kredit investasi dan modal, panjangnya prosedur birokrasi, maraknya pungutan liar dan peraturan yang tidak mendukung masyarakat adalah bukti ketidakmampuan pemerintah dalam memenuhi prasyarat dasar untuk peningkatan daya saing sektorsektor ekonomi. (Adam \& Negara, 2010)

Menurut Setiawan (2012), meskipun China menerima manfaat yang jauh lebih besar dibandingkan manfaat yang diterima Indonesia, manfaat ACFTA dalam jangka panjang memiliki tren yang positif yaitu peningkatan kontribusi ekspor terhadap pendapatan nasional dan pertumbuhannya. Selain itu, kontribusi tersebut juga memberikan dampak turunan bagi sektor-sektor ekonomi yang lain sehingga nantinya juga berkontribusi terhadap pendapatan nasional. Dari penelitian Setiawan (2012) juga menyebutkan bahwa kontribusi ekspor setelah penerapan ACFTA meningkat 1,36 kali lipat jika dibandingkan dengan tidak adanya kebijakan ACFTA.

Harga ekspor kopi Indonesia ke China berpengaruh signifikan terhadap volume ekspor kopi Indonesia ke China dengan signifikansi 5 persen dalam jangka panjang dan jangka pendek. Dari model ECM yang terbentuk, dengan asumsi ceteris paribus, kenaikan 1 persen harga ekspor kopi Indonesia ke China menurunkan 2,31 persen nilai ekspor kopi Indonesia ke China. Hal tersebut sesuai dengan salah satu faktor yang memengaruhi ekspor menurut Mankiw (2011) yaitu harga barang. Dengan asumsi ceteris paribus, kenaikan harga suatu komoditas akan mengurangi ekspor akan komoditas tersebut.

Harga teh dunia berpengaruh signifikan terhadap volume ekspor kopi Indonesia ke China dengan signifikansi 5 persen dalam jangka panjang dan jangka pendek. Dari model ECM yang terbentuk, dengan asumsi ceteris paribus, kenaikan 1 persen harga teh dunia meningkatkan 4,22 persen nilai ekspor kopi Indonesia ke China. Hal tersebut sesuai dengan salah satu faktor yang memengaruhi ekspor menurut Mankiw (2011) yaitu harga barang. Jika barang lain/barang pengganti harganya naik, maka ekspor terhadap barang tersebut meningkat karena lebih memilih barang dengan harga yang lebih murah.

Nilai tukar riil rupiah terhadap yuan berpengaruh signifikan terhadap nilai ekspor kopi Indonesia ke China dengan signifikansi 10 persen dalam jangka panjang dan jangka pendek. Dari model ECM yang terbentuk, dengan asumsi ceteris paribus, kenaikan 1 persen nilai tukar riil rupiah terhadap yuan meningkatkan 6,49 persen nilai ekspor kopi Indonesia ke China. Hal tersebut sesuai dengan salah satu faktor yang memengaruhi ekspor menurut Mankiw (2011) bahwa nilai tukar riil yang tinggi menyebabkan harga barang domestik menjadi murah, sehingga negara lain memilih untuk melakukan impor dari negara kita.

Nilai adjusted $R$-Squared sebesar 0,6102 menunjukkan bahwa secara bersama-sama dalam jangka pendek nilai ekspor kopi Vietnam ke China, harga teh dunia, harga ekspor kopi Indonesia ke China, nilai tukar riil rupiah terhadap yuan, dan dummy pemberlakuan ACFTA mampu menjelaskan keragaman pada volume ekspor kopi Indonesia ke China sebesar 61,02 persen sedangkan sisanya sebesar 38,98 persen dijelaskan oleh variabel lain diluar model.

Model ECM menggunakan koefisien ECT yang menunjukkan seberapa cepat ketidakseimbangan pada periode sebelumnya terkoreksi pada periode sekarang. Berdasarkan model ECM yang terbentuk, nilai dari koefisien ECT adalah -0,8787. Artinya ketidakseimbangan pada triwulan sebelumnya akan terkoreksi sebesar 87,87 persen pada triwulan setelahnya akibat pengaruh jangka pendek dari nilai ekspor kopi Vietnam ke China, harga teh dunia, harga ekspor kopi Indonesia ke China, nilai tukar riil rupiah terhadap yuan, dan pemberlakuan ACFTA. Sementara itu, sebesar 12,13 persen akan terkoreksi pada triwulan-triwulan berikutnya. Dibutuhkan 2 triwulan agar ketidakseimbangan terkoreksi menuju keseimbangan jangka panjang.

Beberapa hasil penelitian sesuai dengan penelitian-penelitian terdahulu, seperti penelitian dari Hussien (2015) bahwa nilai tukar riil memiliki pengaruh dalam peningkatan ekspor kopi dan penelitian dari Ginting (2016) bahwa harga teh, harga ekspor kopi, dan nilai tukar riil berpengaruh terhadap ekspor kopi Indonesia. Penelitian dari Bowo (2012) memiliki perbedaan karena pada penelitian ini pemberlakuan ACFTA tidak signifikan memengaruhi ekspor Indonesia, khususnya komoditas kopi Indonesia. Hal tersebut berarti pemberlakuan ACFTA memiliki pengaruh yang berbeda pada komoditi yang berbeda. 


\section{KESIMPULAN}

Berdasarkan analisis yang telah dilakukan dapat disimpulkan bahwa volume ekspor kopi Indonesia ke China cenderung meningkat setelah ACFTA berlaku secara efektif, dimana pertumbuhannya mengikuti masa panen pada triwulan ketiga, dalam jangka pendek harga teh dunia dan nilai tukar riil rupiah terhadap yuan signifikan berpengaruh positif sementara harga ekspor kopi Indonesia berpengaruh negatif terhadap volume ekspor kopi Indonesia ke China. Dalam jangka panjang, nilai ekspor kopi Vietnam ke China, harga teh dunia, harga ekspor kopi Indonesia ke China, nilai tukar riil rupiah terhadap yuan, dan penerapan ACFTA berpengaruh signifikan terhadap volume ekspor kopi Indonesia ke China. Dibutuhkan waktu selama 2 triwulan untuk mengoreksi keseimbangan jangka panjang.

Beberapa saran yang dapat disampaikan berdasarkan hasil penelitian ini adalah pemerintah dapat memberikan bantuan modal alat/teknologi pertanian dan pemberian informasi yang terkait teknologi kepada petani kopi dalam rangka peningkatan mutu agar ekspor kopi Indonesia meningkat dan lebih stabil, selain itu pemerintah dapat menjaga stabilitas harga kopi, salah satunya dengan meningkatkan mutu kopi agar kopi Indonesia tetap memiliki harga yang tinggi di pasar global meskipun ekspornya tinggi.

\section{UCAPAN TERIMA KASIH}

Penulis mengucapkan terima kasih kepada Badan Pusat Statistik yang telah menyediakan data untuk penelitian ini. Selanjutnya, penulis juga berterima kasih kepada pihak-pihak yang telah ikut menyumbang ide, saran, dan dukungan sehingga penelitian ini dapat dilakukan sebagaimana mestinya.

\section{REFERENSI}

Adam, L \& Negara, S D, (2012), 'ASEAN China Free Trade Agreement: Tantangan dan Peluang bagi Indonesia', Lembaga Ilmu Pengetahuan Indonesia, XXXVI(1).

Atmadji, E, Priyadi, U \& Achiria, S. (2019), 'Perdagangan Kopi Vietnam dan Indonesia di Empat Negara Tujuan Ekspor Kopi Utama: Penerapan Model Constant Market Share’, JIEP, 19(1).

Basuki, A. T. \& Prawoto, N. (2014), Pengantar Teori Ekonomi, Mitra Pustaka Mandiri, Yogyakarta.

Bowo, H. (2012), Dampak Penerapan ASEAN China Free Trade Area (ACFTA) Terhadap Nilai Perdagangan Indonesia atas China: Studi Beberapa Komoditas Terpilih, tesis, Universitas Indonesia.

Desnky, R, Syaparuddin, \& Aminah, S, (2018), 'Ekspor Kopi Indonesia dan Faktor-faktor yang Mempengaruhinya', e-Jurnal Perdagangan, Industri dan Moneter, 6(1).

Enders, W. (2014), Applied Econometric Time Series Fourth Edition, Wiley.

Ginting, C P. (2016), Analisis Ekspor Kopi Indonesia ke Lima Negara ASEAN Tahun 1997-2014, skripsi, Politeknik Statistika STIS.

Gujarati, D. N. (2004), Basic Econometrics, 4th edition, McGraw-Hill Inc.

Hanani, N, Asmara, R \& Fahriyah (2013), Persaingan Ekspor Kopi Indonesia di Pasar Internasional, Jurnal Perhepi, dilihat 6 Juli 2020, <http://nuhfil.lecture.ub.ac.id/files/2012/12/jurnal-kopiperhepinuhfi.pdf>.

Hussien, H B. (2015), 'Determinants of Coffee Export Supply in Ethiopia: Error Correction Modeling Approach', Journal of Economics and Sustainable Development, 6(5).

International Coffe Organization (2019), Country Coffee Profile: Vietnam, International Coffee Council, dilihat 7 Juni 2020, <http://www.ico.org/documents/cy2018-19/icc-124-9e-profilevietnam.pdf $>$.

Mankiw, G. (2011), Principles of Economics, 6th edition, Cengage Learning. 
Nabila, E (2017), Faktor-faktor Defisit Neraca Perdagangan Indonesia dengan Tiongkok (20122014), skripsi, Universitas Katolik Parahyangan.

Pusat Data dan Sistem Informasi Pertanian (2017), Outlook Kopi, Kementerian Pertanian Republik Indonesia, Jakarta.

Pusat Data dan Sistem Informasi Pertanian (2019), Outlook Kopi, Kementerian Pertanian Republik Indonesia, Jakarta.

Rahardjo, P. (2012), Kopi, Penebar Swadaya, Jakarta.

Rahardjo, P. (2017), Berkebun Kopi, Penebar Swadaya, Jakarta.

Rahmawan, N B. (2017), Analisis Ekspor Batu Bara Indonesia ke Tiongkok dengan Pendekatan Error Correction Mechanism dan Model Intervensi Periode 2014 sampai 2016, skripsi, Politeknik Statistika STIS.

Setiawan, A E, \& Sugiarti, T. (2016), 'Daya Saing dan Faktor Penentu Ekspor Kopi Indonesia ke Malaysia dalam Skema Cept-AFTA', Agriekonomika, 5(2).

Setiawan, S. (2012), 'ASEAN-China FTA: Dampaknya Terhadap Ekspor Indonesia dan China', Buletin Ilmiah Litbang Perdagangan, 6(2).

Sheng, Y, Tang, H C, \& Xu, X. (2014), 'The Impact of the ACFTA on ASEAN-PRC Trade: Estimates Based on an Extended Gravity Model for Component Trade', Applied Economics, 46(19), 2251-2263.

Zhu, R (2018), Coffe Market in China, thesis and dissertation - Agricultural economics, University of Kentucky. 